\title{
Combustion synthesis of cadmium sulphide nanomaterials for efficient visible light driven hydrogen production from water
}

\author{
A DAYA MANI ${ }^{\mathrm{a}}$, N XANTHOPOULOS ${ }^{\mathrm{b}}$, DANIELE LAUB $^{\mathrm{b}}$ and C H SUBRAHMANYAM ${ }^{\mathrm{a}, *}$ \\ ${ }^{a}$ Department of Chemistry, Indian Institute of Technology (IIT), Hyderabad, Yeddumailaram 502 205, India \\ ${ }^{\mathrm{b}}$ Ecole Polytechnique Federale de Lausanne (EPFL), CH-Lausanne, Switzerland \\ e-mail: csubbu@iith.ac.in
}

MS received 29 October 2013; revised 7 January 2014; accepted 6 February 2014

\begin{abstract}
Anion-doped cadmium sulphide nanomaterials have been synthesized by using combustion method at normal atmospheric conditions. Oxidant/fuel ratios have been optimized in order to obtain CdS with best characteristics. Formation of CdS and size of crystallite were identified by X-ray diffraction and confirmed by transmission electron microscopy. X-ray photoelectron spectroscopy confirmed the presence of $\mathrm{C}$ and $\mathrm{N}$ in the CdS matrix. The observed enhanced photocatalytic activity of the CdS nanomaterials for the hydrogen production from water $(2120 \mu \mathrm{mol} / \mathrm{h})$ can be attributed to high crystallinity, low band gap and less exciton recombination due to the $\mathrm{C}$ and $\mathrm{N}$ doping.
\end{abstract}

Keywords. Cadmium sulphide; combustion synthesis; anion doping; water splitting; $\mathrm{H}_{2}$ production.

\section{Introduction}

Emission of oxides of carbon due to combustion of fossil fuels has made global warming a difficult task to handle. ${ }^{1}$ As fossil fuel reserves are also depleting, there is an immediate need to look for renewable and/or clean energy sources that are free of carbon. In this context, research on direct utilization of solar energy has been increasing. ${ }^{2}$ It is believed that in future, hydrogen may supersede the current non-renewable resources., Traditional steam-methane reforming for hydrogen production is not an environment-friendly method and there is an immediate need to look for eco-friendly alternatives. Among the several methods for hydrogen production, ${ }^{5-7}$ photocatalytic water splitting is gaining much attention due to its sustainable and environmentally benign nature. ${ }^{8}$ However, the design of suitable materials that are active under sunlight still remains a challenge.

Among the materials available for harnessing solar energy, semiconductor nanostructures are gaining importance owing to their unique optical, electronic and catalytic properties. Cadmium sulphide (CS) with a direct band gap of $2.4 \mathrm{eV}$ is one of the first semiconductors to be discovered. It is perhaps one of the most important electronic and optoelectronic materials

*For correspondence with proven applications in solar cells, nonlinear optical devices and electronic devices. ${ }^{9-11} \mathrm{CdS}$ has been extensively studied as a photocatalyst for the degradation of organic dyes, but its usage in hydrogen production studies is rather limited due to its photocorrosive nature. $^{12,13}$

Designing CdS nanomaterials with matching redox potentials for the aforementioned applications is of great interest in material science. Although a variety of techniques such as thermal evaporation, hydrothermal method, chemical vapor deposition process, template method, thermal decomposition method and solvothermal process are reported for the preparation of $\mathrm{CdS}$ quantum dots, many of them demand complicated procedures, inert conditions and longer reaction times and use of costly surfactants to produce CdS with different morphologies. ${ }^{14-19}$ In this context, combustion synthesis with less energy payback time (a key parameter in life cycle analyses of solar energy materials and devices) is receiving more attention, especially for synthesis of oxides. ${ }^{20-22}$

However, application of combustion for the synthesis of metal chalcogenides is not fully explored. To the best of our knowledge, this is probably the first attempt of metal sulphide synthesis by using solution combustion method without maintaining any inert conditions. This study reports a facile synthesis of $\mathrm{C}$ and $\mathrm{N}$ doped CdS nanomaterials. Synthesized CdS nanomaterials have been tested for the visible light-driven hydrogen production from water splitting. 


\section{Experimental}

Cadmium nitrate tetrahydrate and thiourea were purchased from Merck and used as received. Required quantities of precursors were calculated based on the oxidant/fuel $(\mathrm{O} / \mathrm{F})$ ratio obtained by using propellant theory. In a typical synthesis, aqueous solutions of cadmium nitrate and thiourea were mixed to form a homogeneous solution. Dehydration followed by combustion in a preheated furnace at $300^{\circ} \mathrm{C}$ resulted the product in a few minutes. Different oxidant/fuel $(\mathrm{O} / \mathrm{F})$ ratios $(1,2,3$, 4 and 10) have been studied and the resulting CdS samples were labelled as CdS (1), CdS (2), CdS (3), CdS (4) and CdS (10), respectively. Since costly surfactants, capping agents and inert conditions are not used in this synthesis, it is a very cost-effective method. Moreover, the samples can be used without any post-treatments such as washing and calcination.

\subsection{Characterization}

Cadmium sulphide samples were characterized to examine its structural, morphological, and optical properties. Phase purity and crystallinity of the assynthesized CdS samples were obtained from powder X-ray diffraction (PXRD) patterns recorded on a PANalytical X'pert Pro powder X-ray diffractometer with a step size of 0.02 at a scan rate of $0.50 \mathrm{~min}^{-1}$ using $\mathrm{Cu}-\mathrm{K} \alpha(1.54 \AA)$ radiation and Ni filter. Transmission electron microscopic image of the $\mathrm{CdS}(2)$ sample was recorded at an operating voltage of $200 \mathrm{kV}$ and the sample was placed on a copper grid (TECNAI G-2 with EDS model), whereas, diffuse UV-Vis reflectance spectra of the prepared samples were collected using Shimadzu UV-Vis spectrophotometer (UV3600) with spectral grade $\mathrm{BaSO}_{4}$ as reference. X-ray photoelectron spectroscopic study was performed on Axis Ultra instrument under ultra-high vacuum condition $\left(<10^{-8}\right.$ Torr $)$ and by using a monochromatic Al $\mathrm{K} \alpha \mathrm{X}$-ray source $(1486.6 \mathrm{eV})$. Raman spectra of the assynthesized samples were carried out with a dispersive Raman spectroscope (Bruker Senterra).

\subsection{Photocatalytic reactions}

Photocatalytic water splitting under simulated visible light radiation was performed in a quartz roundbottomed flask containing $100 \mathrm{~mL}$ water and $100 \mathrm{mg}$ of the catalyst. The study was carried out in the presence of $1 \mathrm{M} \mathrm{Na}_{2} \mathrm{~S}$ and $1 \mathrm{M} \mathrm{Na}_{2} \mathrm{SO}_{3}$ as the sacrificial reagents. Before addition of CdS catalyst, $\mathrm{N}_{2}$ was bubbled for $30 \mathrm{~min}$, followed by evacuation for $15 \mathrm{~min}$ to remove the dissolved gases. After addition of the $\mathrm{CdS}$ catalyst, the solution was stirred in dark for $30 \mathrm{~min}$ in order to facilitate the adsorption of water molecules on the CdS surface. It is worth mentioning that there is no appreciable reaction in the dark. All the studies were carried out under simulated visible light radiation with light intensity around $800-900 \mathrm{~W} / \mathrm{m}^{2}$, as measured by Newport power meter. Hydrogen produced in the reaction was analysed by using a Shimadzu gas chromatography (GC-2014) equipped with TCD detector, packed column and $\mathrm{N}_{2}$ carrier gas. Every hour, a $500 \mu 1$ hydrogen gas was collected in a gas tight syringe (Hamilton) and injected into the GC. Calibration curve has been drawn by taking different volumes of pure $\mathrm{H}_{2}$ and injecting into the GC. The area under the evolved $\mathrm{H}_{2}$ gas was compared with the area under the calibration curve and quantified in terms of $\mu \mathrm{mol}$.

\section{Results and Discussion}

\subsection{Powder X-ray diffraction}

Combustion-synthesized cadmium sulphide samples with varying $\mathrm{O} / \mathrm{F}$ ratios from 1 to 10 were characterized by PXRD to identify phase purity and crystallite size. As shown in figure 1 , except in the case of $\mathrm{O} / \mathrm{F}$ ratio 1 , pure $\mathrm{CdS}$ was observed for other ratios. $\mathrm{CdS}$ (1) with more intense diffraction peaks at d-spacing of 2.7, 2.4 and $1.7 \AA$ with corresponding planes (111), (200) and (220) confirms the existence of CdO. This can be attributed to insufficient fuel, thiourea. CdS (2) shows major peaks at $2 \theta ;=28.2^{\circ}, 24.8^{\circ}, 43.7^{\circ}, 26.5^{\circ}$

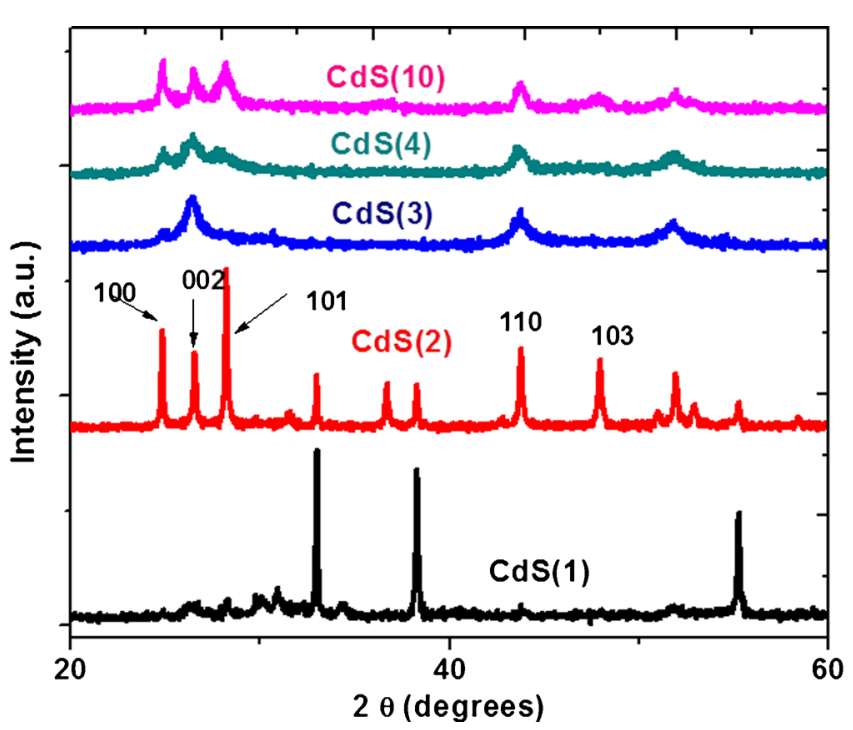

Figure 1. Powder X-ray diffraction patterns of combustion-synthesized cadmium sulphide samples. 
and $47.9^{\circ}$ corresponding to $101,100,110,002$ and 103 planes with the corresponding d-spacing values are 3.6, 3.4, 3.2, 2.1 and $1.9 \AA$ representing hexagonal $\mathrm{CdS}$. From figure 1, it was observed that $\mathrm{CdS}$ (3) and $\mathrm{CdS}(4)$ also have diffraction peaks corresponding to the hexagonal phase. However, in the case of CdS (3), the peaks corresponding to (101), (100) and (002) planes seems overlapped due to the small crystallite size (around $14 \mathrm{~nm})$. However, for CdS(4) and CdS(10), these peaks are distinguishable due to large crystallite size (around $25 \mathrm{~nm})$.

Generally, broadening of diffraction peak may be due to one of the following factors such as micro strain (deformations of the lattice), crystalline faults (extended defects), crystalline size and domain size distribution. ${ }^{23-25}$ Average crystallite sizes of the CdS samples calculated by using Scherrer formula was found to be 58, 70, 14, 20 and $25 \mathrm{~nm}$ for CdS (1), CdS (2), CdS (3), CdS (4) and CdS (10), respectively. Larger crystallite size in case of $\mathrm{CdS}$ (2) may be explained on the basis of optimum $\mathrm{O} / \mathrm{F}$ ratio, which facilitates the combustion and provides high temperatures for crystal growth. ${ }^{13}$

\subsection{Transmission electron microscopy}

In order to confirm the phase and crystallite size, TEM studies were carried out for all the CdS samples. Figure 2 shows TEM image of best active CdS(2) sample, whereas TEM images of all the remaining CdS samples are given in supporting information (figure $\mathrm{S} 1$ to $\mathrm{S} 4$ ). From figure $2 \mathrm{a}$, it is clear that $\mathrm{CdS}(2)$ sample consists of some irregular-shaped crystalline nanoparticles. Particle size was found to be around $70 \mathrm{~nm}$ which is in good agreement with the PXRD results. Selected area electron diffraction pattern (figure $2 b$ ) with $d$ spacing corresponding to the planes (100), (002), (103) and (110) confirmed the hexagonal CdS phase which is also in good agreement with the XRD results. From figure $\mathrm{S} 1$ to $\mathrm{S} 4$, it is clear that $\mathrm{CdS}(1), \mathrm{CdS}(3), \mathrm{CdS}(4)$ and $\mathrm{CdS}(10)$ samples have several nanoparticles with almost spherical morphology. Thus, the best activity of $\mathrm{CdS}(2)$ might be attributed to its good crystalline nature as confirmed by XRD rather than its morphology.

\subsection{Diffuse UV-Vis spectroscopy}

It is well-known that $\mathrm{CdS}$ is a direct band gap semiconductor with a band gap energy of $2.4 \mathrm{eV}$. A red shift in the absorption due to $\mathrm{C}$ and $\mathrm{N}$ doping was recognized from absorption spectra of the combustion-synthesized CdS samples (figure 3). Band gap energies of CdS (1), $\mathrm{CdS}(2), \mathrm{CdS}(3), \mathrm{CdS}(4)$ and $\mathrm{CdS}$ (10) samples were

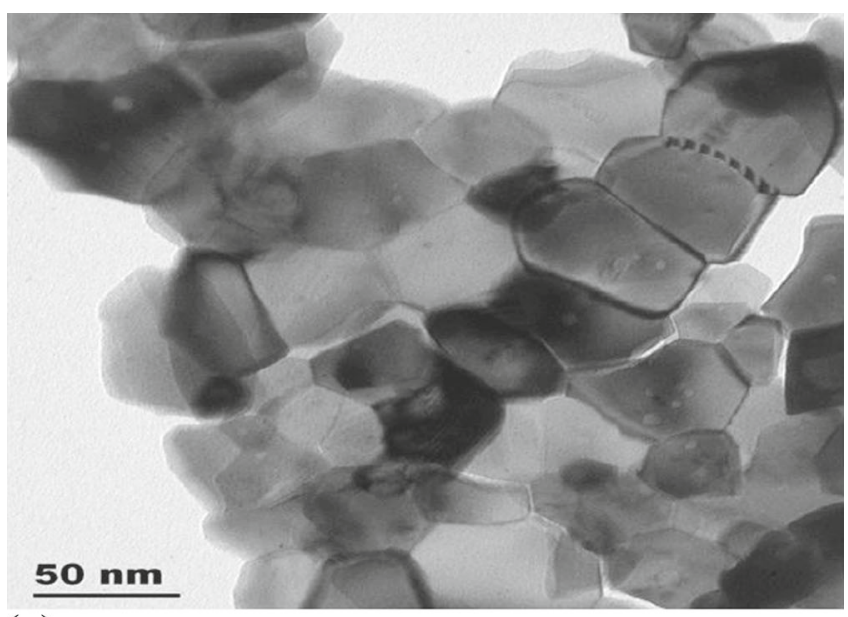

(a)

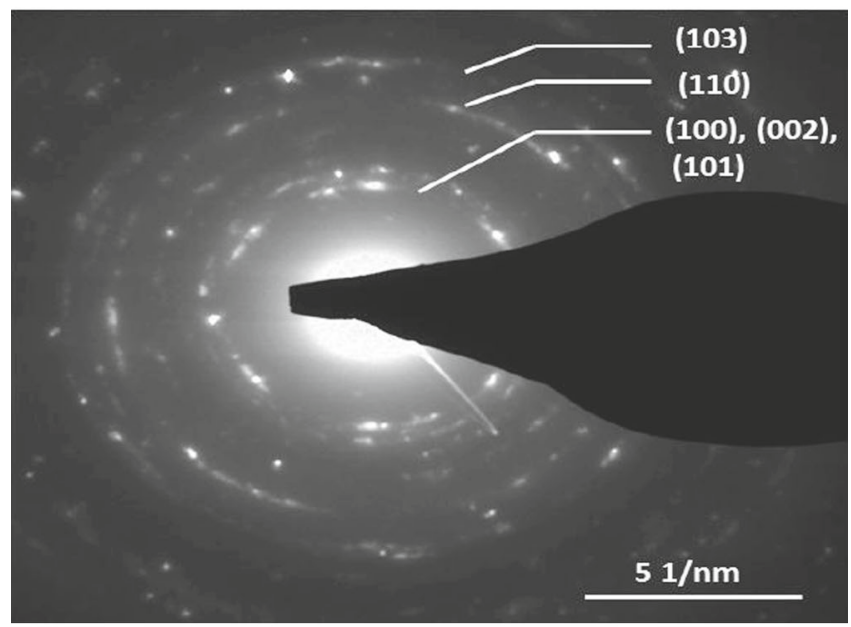

(b)

Figure 2. (a) TEM image of the best active CdS (2) sample which shows irregular-shaped nanoparticles. (b) Selected area electron diffraction pattern of the $\mathrm{CdS}(2)$ sample showing different planes corresponding to the hexagonal $\mathrm{CdS}$ phase.

found to be 2.0, 2.2, 2.3, 2.4 and $2.4 \mathrm{eV}$, respectively. Band gap energy of $2.0 \mathrm{eV}$ in case of $\mathrm{CdS}$ (1) could be attributed to the $\mathrm{C}$ and $\mathrm{N}$ doped $\mathrm{CdO}$ (band gap of $\mathrm{CdO}$ is $2.16 \mathrm{eV}$ ). Among CdS (2), CdS (3), CdS (4) and CdS (10) samples, CdS (2) was found to have a low band gap of $2.2 \mathrm{eV}$, probably due to more $\mathrm{C}$ and $\mathrm{N}$ doping compared to the rest of the samples and with increasing $\mathrm{O} / \mathrm{F}$ ratio from 3 to 10 band gap again increased to the original value of $2.4 \mathrm{eV}$ due to fuel rich conditions, which hindered proper combustion. Higher $\mathrm{C}$ and $\mathrm{N}$ doping in $\mathrm{CdS}(2)$ sample compared to the other $\mathrm{CdS}$ samples can be explained as follows: In general, $\mathrm{O} / \mathrm{F}$ ratio of 1 is the optimum ratio for the combustion synthesis of materials. However, in the present synthesis, $\mathrm{O} / \mathrm{F}=2$ is the optimum ratio in such a way that it is small enough to produce the sulphide phase at normal atmospheric conditions as well as to produce proper 


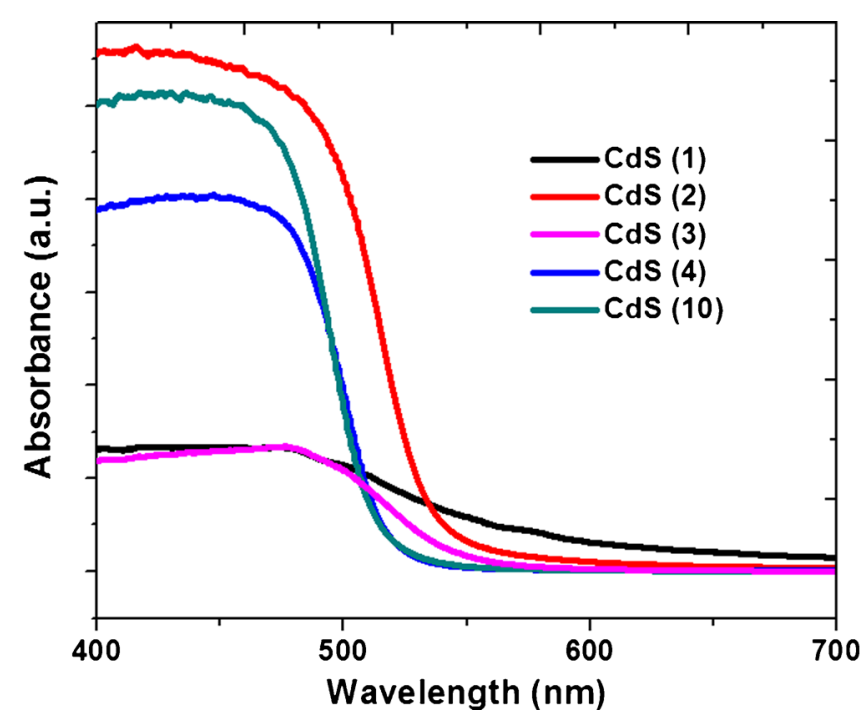

Figure 3. Diffuse reflectance UV-Vis spectra of combustion-synthesized CdS samples.

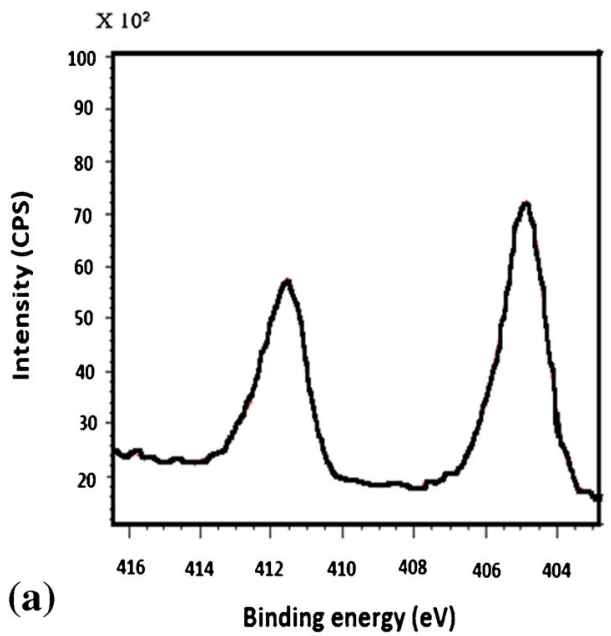

(b)
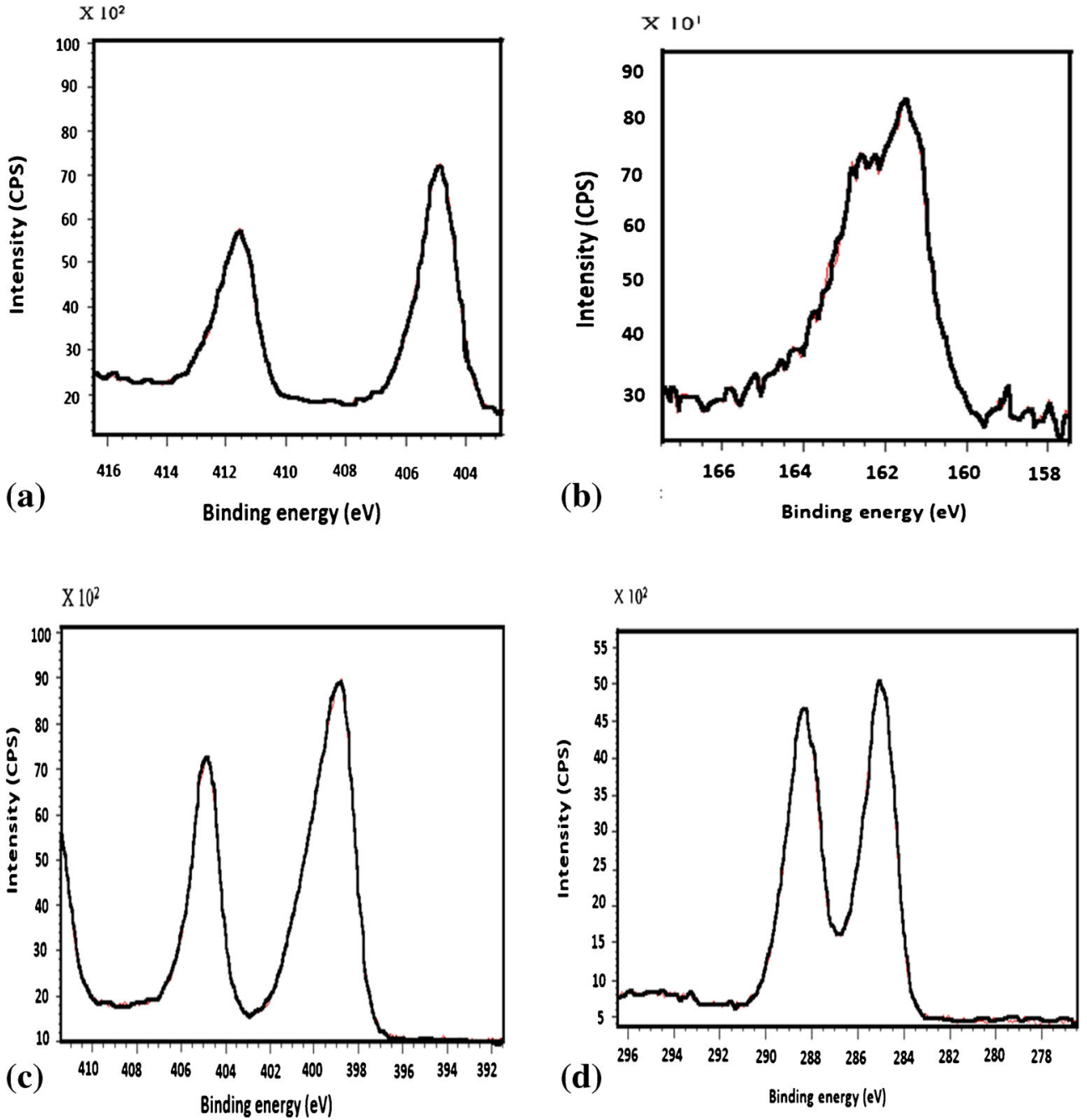

combustion conditions with more evolved gases. Thus, in case of $\mathrm{CdS}(2)$ sample, optimum $\mathrm{O} / \mathrm{F}$ ratio has been achieved that might facilitate proper combustion, which in turn enables proper $\mathrm{C}$ and $\mathrm{N}$ doping into the $\mathrm{CdS}$ matrix.

\section{$3.4 \quad X$-ray photoelectron spectroscopy}

In order to confirm the presence of $\mathrm{C}$ and $\mathrm{N}$ doping, XPS study of CdS (2) sample was carried out and the spectra are shown in figure 4. As seen in figure 4a, Cd (3d) spectra showed two peaks centered at 405.2 and $411.9 \mathrm{eV}$, characteristic of $\mathrm{Cd} 3 \mathrm{~d}_{5 / 2}$ and $\mathrm{Cd} 3 \mathrm{~d}_{3 / 2}$, respectively. ${ }^{26-29}$ Whereas the $\mathrm{S} 2 \mathrm{p}$ peak observed at $161.5 \mathrm{eV}$ and $162.7 \mathrm{eV}$ as shown in figure $4 \mathrm{~b}$ inferred the existence of sulphides. Absence of peaks centered at 165 and $170 \mathrm{eV}$ reveals the existence of sulphur in non-oxidized form.

Figure 4. XPS spectra of (a) Cd 3d core levels, (b) S 2p core levels, (c) C 1s core levels, (d) $\mathrm{N} 1 \mathrm{~s}$ core levels of the best active CdS (2) sample. 

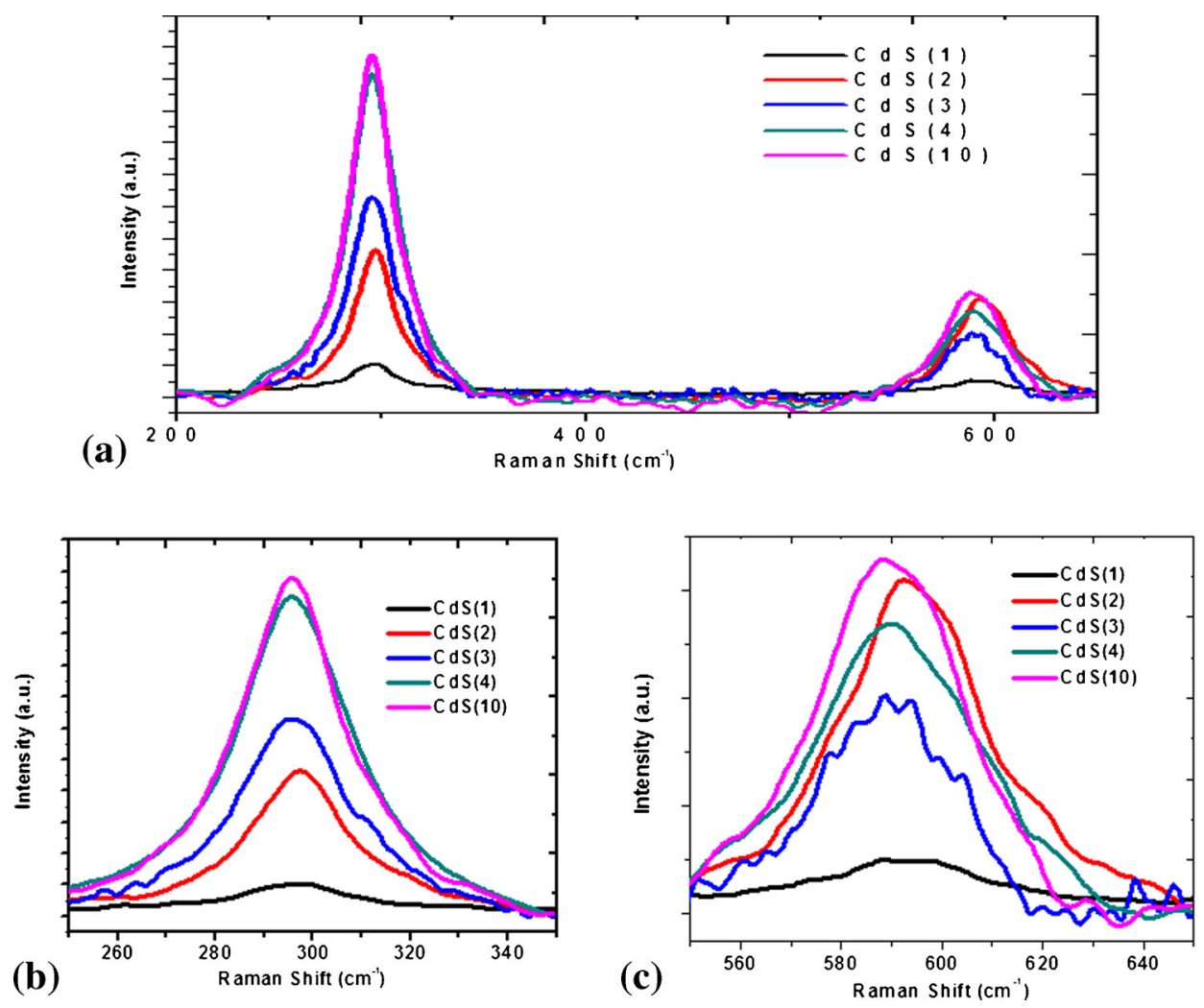

Figure 5. (a) Raman spectra of CdS samples. (b) Enlarged view of A11LO phonon mode of CdS samples. (c) Enlarged view of A1 2LO phonon mode of CdS samples.

Presence of $\mathrm{C}$ as a dopant was clearly shown by the peaks at 285 and $289 \mathrm{eV}$ in the deconvoluted $\mathrm{C} 1 \mathrm{~s}$ spectra as represented in figure $4 \mathrm{c}$. The former peak might occur due to the aliphatic carbon, whereas the latter one occurred due to the $\mathrm{C}$ bonded with $\mathrm{O}$ and/or $\mathrm{S}$, either with a double bond or two single bonds. ${ }^{30} \mathrm{Simi}$ larly, evidence for nitrogen doping was provided from the $N(1 \mathrm{~s})$ spectra that showed two peaks at 399.7 and $405 \mathrm{eV}$ (figure 4d). Literature data confirmed that binding energy of the $\mathrm{N} 1 \mathrm{~s}$ was very sensitive to the chemical environment of nitrogen and it varies from 396 to $408 \mathrm{eV}^{31}$ The peaks observed at $399.7 \mathrm{eV}$ correspond to the terminally bonded well-screened molecular nitrogen $\left(\gamma-\mathrm{N}_{2}\right)$, whereas, the $405 \mathrm{eV}$ peak might occur due to terminally bonded poorly screened molecular nitrogen $\left(\gamma-\mathrm{N}_{2}\right){ }^{32}$

\subsection{Raman spectra}

Hexagonal CdS is one of the simple uniaxial structures that can be analysed by Raman scattering phenomena. ${ }^{33}$ Figure 5a presents Raman spectra of the synthesized $\mathrm{CdS}$ samples, whereas figure $5 \mathrm{~b}$ and $\mathrm{c}$ showed enlarged views of the A11LO and AL2LO phonon modes of $\mathrm{CdS}$, respectively. It represents two distinct Raman bands in the spectral region of 200 to $700 \mathrm{~cm}^{-1}$. Raman bands at 299 and $600 \mathrm{~cm}^{-1}$ correspond to the A1 $1 \mathrm{LO}$ (longitudinal optical) and A1 2LO phonons, respectively and the intensity of A1 $2 \mathrm{LO}$ phonon at $600 \mathrm{~cm}^{-1}$ was lower compared to the intensity of A1 $1 \mathrm{LO}$ mode at $299 \mathrm{~cm}^{-1} \cdot{ }^{34-38}$ As seen clearly from figure $5 \mathrm{~b}$ and c that with increasing $\mathrm{O} / \mathrm{F}$ ratio, the peak shifted to lower

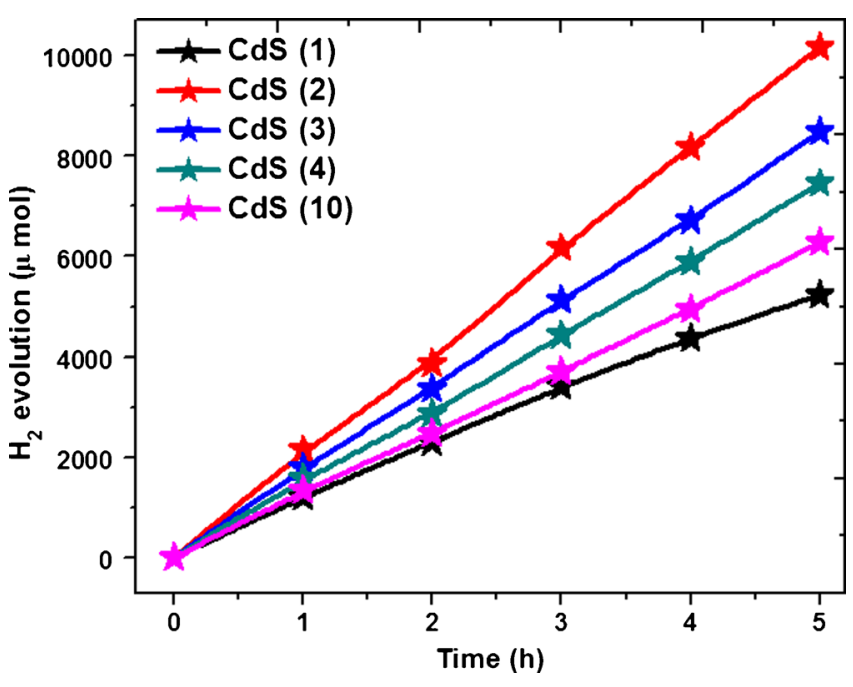

Figure 6. Photocatalytic $\mathrm{H}_{2}$ evolution profiles from splitting of water containing $\mathrm{Na}_{2} \mathrm{~S}$ and $\mathrm{Na}_{2} \mathrm{SO}_{3}$ sacrificial reagents under visible light in the presence of different $\mathrm{CdS}$ samples. 
frequency region and full width half maxima (FWHM) increased due to the difference in the crystalline sizes.

\subsection{Photocatalytic studies}

Since CdS is well-known for its visible light activity and also the in situ doping of $\mathrm{C}$ and $\mathrm{N}$ into the $\mathrm{CdS}$ has been confirmed, visible light activity of the $\mathrm{CdS}$ was tested for hydrogen production from water. Although CdS has good absorption in the visible region, its photocorrosive nature limits its application in $\mathrm{H}_{2}$ production. ${ }^{39}$ In order to reduce photocorrosion of $\mathrm{CdS}$ and to prevent recombination of excitons, water containing $1 \mathrm{M} \mathrm{Na}_{2} \mathrm{~S}$ and $1 \mathrm{M} \mathrm{Na}_{2} \mathrm{SO}_{3}$ as sacrificial reagents were used. These sacrificial reagents may interact with the holes that prevent photocorrosion of CdS catalyst. ${ }^{39}$ During the photocatalytic reaction, for every $1 \mathrm{~h}, \mathrm{H}_{2}$ gas was collected by using a gas tight syringe and analysed by gas chromatography. Typical chromatogram observed is shown in figure S5 (supporting information). $\mathrm{H}_{2}$ production studies were carried out with all the CdS samples and the typical results shown in figure 6 confirmed the formation of 1215, 2135, 1800, 1590 and $1345 \mu \mathrm{mol} / \mathrm{h}$ of hydrogen, respectively for CdS (1), CdS (2), CdS (3), CdS (4) and CdS (10). These results confirmed that the highest hydrogen evolution was achieved for CdS (2). In order to assess the stability of $\mathrm{CdS}(2)$ photocatalyst for hydrogen production, the activity was monitored for $25 \mathrm{~h}$ by evacuating the reactor after every $5 \mathrm{~h}$ and the results are shown in figure 7. After $25 \mathrm{~h}$, decrease in $\mathrm{H}_{2}$ production was

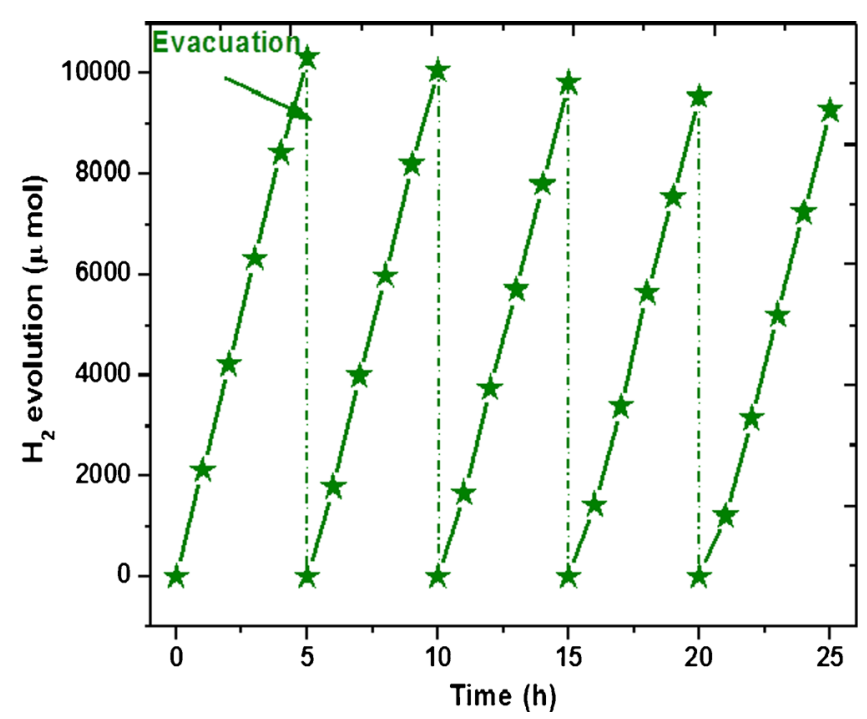

Figure 7. $\mathrm{H}_{2}$ evolution profiles from water containing $\mathrm{Na}_{2} \mathrm{~S}$ and $\mathrm{Na}_{2} \mathrm{SO}_{3}$ sacrificial agents in the presence of $\mathrm{CdS}$ (2) (five runs in a continuous reaction are shown). found to be approximately $10 \%$ confirming the reasonable stability of the catalyst. The best activity of $\mathrm{CdS}(2)$ can be attributed to the higher crystallinity and low band gap, due to which it has the best absorption in the visible region.

\section{Conclusions}

A highly efficient synthesis of $\mathrm{C}$ and $\mathrm{N}$ doped nanocrystalline $\mathrm{CdS}$ has been reported by using solution combustion synthesis without using any surfactant. Variation of $\mathrm{O} / \mathrm{F}$ ratio between 1 and 10 revealed that the sample synthesized at $\mathrm{O} / \mathrm{F}$ ratio of 2 had the best photocatalytic activity. Efficient hydrogen production of $2120 \mu \mathrm{mol} / \mathrm{h}$ from water containing $1 \mathrm{M} \mathrm{Na}_{2} \mathrm{~S}$ and $1 \mathrm{M}$ $\mathrm{Na}_{2} \mathrm{SO}_{3}$ as sacrificial agents under visible light irradiation validated the synthesis approach. The best activity of CdS(2) may be attributed to the good absorption in the visible region, resistance to photocorrosion and prevention of excition recombination by the dopant energy levels.

\section{Supplementary information}

TEM images of the $\operatorname{CdS}(1), \operatorname{CdS}(3), \operatorname{CdS}(4)$ and $\mathrm{CdS}(10)$ samples and the corresponding discussion is provided in the supplementary information. Gas chromatogram observed during the $\mathrm{H}_{2}$ analysis was included in the revised manuscript.

\section{Acknowledgement}

Ms. Daya Mani would like to thank MHRD, India for UGC-JRF fellowship.

\section{References}

1. Cox P M, Betts R A, Jones C D, Spall S A and Totterdell I J 2000 Nature 408184

2. Coelho B, Oliveira A C and Mendes A 2010 Energy Environ. Sci. 31398

3. Jacobson M Z, Colella W G and Golden D M 2005 Science 3081901

4. Jain I P 2009 Int. J. Hydrogen Energ. 347368

5. Li C and Fang H H P 2007 Crit. Rev. Env. Sci. Technol. 371

6. Holladay J D, Hu J, King D L and Wang Y 2009 Catal. Today 139244

7. Onuki K, Kubo S, Terada A, Sakaba N and Hino R 2009 Energy Environ. Sci. 2491 
8. Wang X, Maeda K, Thomas A, Takanabe K, Xin G, Carlsson J M, Domen K and Antonietti M 2009 Nat. Mater. 876

9. Pan H, Poh C K, Zhu Y W, Xing G C, Chin K C, Feng Y P, Lin J Y, Sow C H, Ji W and Wee A T S $2008 \mathrm{~J}$. Phys. Chem. C 11211227

10. Lin Y F, Song J H, Ding Y, Lu S Y and Wang Z L 2008 Adv. Mater. 203127

11. Shen G Z, Cho J H, Yoo J K, Yi G C and Lee C J 2005 J. Phys. Chem. B 1099294

12. Apte S K, Garaje S N, Mane G P, Vinu A, Naik S D, Amalnerkar D P and Kale B B 2011 Small 7957

13. Bao N, Shen L, Takata T, Domen K, Gupta A, Yanagisawa K and Grimes C A 2007 J. Phys. Chem. C 11117527

14. Wang Q Q, Xu G and Han G R 2006 Crsyt. Growth Des. 61776

15. Thiruvengadathan R and Regev O 2005 Chem. Mater. 173281

16. Jianzhong J, Yane $\mathrm{H}$, Leping $\mathrm{W}$, Zhe $\mathrm{C}$, Zhenggang $\mathrm{C}$ and Philip G J 2013 Chem. Commun. 491912

17. Bo Z, Weifeng Y, Cunping H, Qunjie X and Qiang W 2013 Int. J. Hydrogen Energ. 387224

18. Jum S J, Upendra A J and Jae S L 2007 J. Phys. Chem. C 11113280

19. Jiaguo Y, Yanfang Y and Bei C 2012 RSC Adv. 211829

20. Rajeshwar K and Tacconi N R D 2009 Chem. Soc. Rev. 381984

21. Guo X, Mao D, Wang S, Wu G and Lu G 2009 Catal. Commun. 101661

22. Zhang Z, Wang W, Shang M and Yin W 2010 Catal. Commun. 11982

23. Klug H P and Alexander L E 1954 X-ray diffraction procedures for polycrystalline and amorphous materials $1 \mathrm{st}$ ed., Chapter 9 (New York: Wiley)
24. Shen L, Bao N, Yanagisawa K, Domen K, Gupta A and Grimes C A 2006 Nanotechnology 175117

25. Shen L, Bao N, Yanagisaw K, Zheng Y, Domen K, Gupta A and Grimes C A 2007 J. Phys. Chem. C 111 7280

26. Zhai T, Fang X, Bando Y, Liao Q, Xu X, Zeng H, Ma Y, Yao J and Golberg D 2009 ACS Nano. 3949

27. Xiong S, Zhang X and Qian Y 2009 Cryst. Growth Des. 95259

28. Katari J E B, Colvin V L and Alivisatos A P $1994 \mathrm{~J}$. Phys. Chem. 984109

29. Wang D, Li D, Guo L, Fu F, Zhang Z and Wei Q 2009 J. Phys. Chem. C 1135984

30. Li Y, Hwang D-S, Lee N H and Kim S-J 2005 Chem. Phys. Lett. 40425

31. Moulder J F, Stickle W F, Sobol P E, Bomben K $\mathrm{D}$ and Chastain J 1992 Handbook of X-ray electron spectroscopy Eden Prairie (MN: Perkin-Elmer Corp.)

32. Shinn N D and Tsang K L 1991 J. Vac. Sci. Technol. A 9 1558

33. Nusimovici M A and Birman J L 1967 Phys. Rev. 156 925

34. Arguello C A, Rousseau D L and Porto S P S 1969 Phys. Rev. 1811351

35. Tell B, Damen T C and Porto S P S 1966 Phys. Rev. 144 771

36. Pan A, Liu R, Yang Q, Zhu Y, Yang G, Zou B and Chen K 2005 J. Phys. Chem. B $\mathbf{1 0 9} 24268$

37. Fan H M, Ni Z H, Feng Y P, Fan X F, Kuo J L, Shen Z X and Zou B S 2007 Appl. Phys. Lett. 91171911

38. Yamamoto A, Endo H, Matsuura N, Ishizumi A and Kanemitsu Y 2009 Phys. Stat. Sol. C 6197

39. Muruganandham M, Ramakrishnan A, Kusumotob Y and Sillanpaa M 2010 Phys. Chem. Chem. Phys. 12 14677 